\title{
Association between Endocrine Disrupting Phenols in Colostrums and Maternal and Infant Health
}

\author{
B. Yi, ${ }^{1}$ C. Kim, ${ }^{2}$ M. Park, ${ }^{3}$ Y. Han, ${ }^{4}$ J. Y. Park, ${ }^{5}$ and M. Yang ${ }^{1}$ \\ ${ }^{1}$ Research Center for Cell Fate Control, Sookmyung Women's University College of Pharmacy, Seoul 140-742, Republic of Korea \\ ${ }^{2}$ Korea Testing \& Research Institute, Gyeonggido 415-871, Republic of Korea \\ ${ }^{3}$ Inje University Sanggye Paik Hospital, Seoul 139-707, Republic of Korea \\ ${ }^{4}$ Mart Pediatric Clinic, Gyeonggido 456-824, Republic of Korea \\ ${ }^{5}$ Division of Cancer Prevention and Controls, Moffitt Cancer Center and Research Institute, 12902 Magnolia Drive, \\ Tampa, FL 33612, USA
}

Correspondence should be addressed to M. Yang; myang@sm.ac.kr

Received 31 December 2012; Accepted 28 March 2013

Academic Editor: Ewa Gregoraszczuk

Copyright (C) 2013 B. Yi et al. This is an open access article distributed under the Creative Commons Attribution License, which permits unrestricted use, distribution, and reproduction in any medium, provided the original work is properly cited.

Bisphenol A (BPA) and alkylphenols (APs) are well-known endocrine disrupting chemicals (EDCs) which may threat the next generations' health. We performed biomonitoring of these phenols in colostrums to assess risk of the phenols in breast-fed neonates. Study subjects were the lactating mothers who delivered babies within 2 weeks $(N=325 ; 30.67 \pm 3.45$ years $)$ and their neonates $(N=326$; embryonic period, $39.1 \pm 1.5$ weeks). BPA, nonylphenol (NP), and octylphenol (OP) in colostrums were quantified with LC/MS/MS. Information for environmental exposure sources of the phenols was obtained by questionnaires. As results, median level of BPA in colostrums was $7.8 \mathrm{ng} / \mathrm{mL}$, while most NP or OP was not detected. Regarding health risks of phenols, levels of total NP in colostrums were elevated among sick mothers with toxemia, thyroid disorders, gastritis, and so forth than health mothers $(3.51 \pm 4.98$ versus $2.04 \pm 3.71 \mathrm{ng} / \mathrm{mL}, P=0.02)$. Dairy products intake and detergents use were positively correlated with total BPA levels $(P s<0.05)$. In conclusion, we estimate most neonates who are exposed to BPA rather than NP or OP via colostrums and recommend continuous biomonitoring of the phenols to clarify their suspected health risk on neonates and pregnant or gestation mothers.

\section{Introduction}

Effects of endocrine disrupting chemicals (EDCs) on human health and wildlife are receiving growing attention for the next generation's health and have been known to interfere with endocrine systems by mimicking, blocking, and triggering actions of hormones and implicated with toxic effects, for example, disorders in development and reproduction [1]. Among EDCs, bisphenol A [BPA, 2,2-bis (4-hydroxyphenyl) propane] is widely used for a variety of applications, for example, baby feeding bottles, food-can lining, and sealants in dentistry. In addition, 4-tertiary-octylphenol (OP) and 4nonylphenol (NP) of alkylphenols (APs) have been used to make alkylphenol ethoxylates, nonionic surfactants applied as emulsifying, wetting, or stabilizing agents in industries, and various consumer products including detergents and pesticide formulations [2]. Due to the wide uses of these phenols, it has been speculated that human exposures to environmental phenols may be widespread [3-6]. Thus, concerns about various adverse health effects caused by EDCs are increasing, and rigid risk assessment for EDCs throughout valid biomonitoring studies has been called for. Particularly, considering low-body weights and susceptibility, we suspect that body burden or real exposure level of infants or children to BPA or APs is expected to be heavier than those of adults. In the view of susceptibility, the exposures to environmental phenols in infants and children have got the public attention because EDCs treat the second generation's health, for example, genital malformations, testicular abnormalities, impairment in fertility or sexual functions, and neonates are considered to be a vulnerable subgroup to xenobiotics $[7,8]$. Therefore, environmental phenols including BPA and APs 
should be continuously monitored for achievements of public heath, particularly for infants and children.

Contamination of ECDs in colostrums raises concerns gravely because neonates, who are solely dependent on colostrums, are considered to be a high susceptible to EDCs. Detoxifying enzymes of neonates would not be fully developed at this early time point and exposure to EDCs during the critical periods of developments could cause morphologic and functional alterations by influencing growth, reproduction, and development $[7,8]$. Considering the characteristics of EDCs that affect the second generation's health, we need biomonitoring of EDCs in colostrum, which is the main route of exposure to EDCs for breast-fed infants. A number of investigations have reported the occurrence of several environmental chemicals such as persistent organic pollutants (POP), polychlorinated dibenzo-dioxins (PCDDs), and organochlorines (OCs) in breast milk [9-11]. BPA, OP, and NP have the potency to partition into breast milk, since they are lipophilic compounds, which have octanol-water partition coefficient value (log $P$ or Kow) around 3-4 $[12,13]$.

Concerning the phenol exposure sources, we have studied various environmental sources; however, we could not find crucial exposure sources, yet $[14,15]$. In a case of NP, dairy products and sea food were suspected as its exposure sources $[16,17]$. In addition, ethoxylation products of APs have been used for cosmetics or surfactants [18]. Thus, we focused on the consumption of dairy products and sea food or the use of cosmetics or surfactants to find phenol exposure routes in this study. In addition, we established a sensitive analytical method for BPA, OP, and NP in human colostrums and performed biomonitoring of these phenols among Korean lactating women's colostrums to assess risk of BPA and APs for breast-fed neonates.

\section{Materials and Methods}

2.1. Study Subjects. Study subjects were 325 lactating mothers, who stayed in postpartum care centers in Seoul, Republic of Korea. All subjects consented to participate in this study and donated their colostrums $(\approx 10 \mathrm{~mL})$. Colostrums were collected in dark glass tubes with glass caps and stored $-20^{\circ} \mathrm{C}$ prior to analyses. We also obtained their questionnaires addressing physical characteristics, lifestyle patterns including dietary habits, and health and pregnancy-related properties [14, 19]. All of the above procedures were approved by the institutional review boards of Inje University, Paek Hospital (Seoul, Republic of Korea).

2.2. Analysis of Phenols in Milk. Throughout the entire procedure, plastic wares were replaced with glassware in order to avoid possible phenol contamination. We analyzed total forms (conjugated and free phenols) and free forms of BPA and APs for each colostrum sample with/without enzyme hydrolysis, respectively. The concentration of conjugated phenols was calculated after subtracting the amount of the free form of phenols from that of total phenols.
To determine total forms of the three phenols levels in colostrum, we established an optimal method with modification of the BPA analysis. In brief, $100 \mathrm{uL}$ of internal standard (125 ng/mL of bisphenol B (BPB), Tokyo Kasei Chemical, Tokyo, Japan), $120 \mathrm{uL}$ of $2.0 \mathrm{M}$ sodium acetate, and $48 \mathrm{uL}$ of $\beta$-glucuronidase $(2,784 \mathrm{U}$ ) (Sigma, St. Louis, MO) were added to $2 \mathrm{~mL}$ of milk samples. The mixture was incubated at $37^{\circ} \mathrm{C}$ for 5 hours; $4 \mathrm{~mL}$ of 2-propanol was added and mixed thoroughly. Thereafter, the mixture was centrifuged $(3,000 \mathrm{~g}, 20 \mathrm{~min})$, and $3 \mathrm{~mL}$ of supernatant was transferred to new glass tubes. This extraction was repeated, and total transferred $6 \mathrm{~mL}$ of supernatant was evaporated. After the evaporation, the residue was dissolved with $250 \mathrm{uL}$ of $60 \%$ acetonitrile, and this solution was centrifuged (14,000 rpm, $10 \mathrm{~min}$ ). Thereafter, $200 \mathrm{uL}$ of the supernatant was transferred to a vial, and $50 \mathrm{uL}$ of the supernatant was injected for LC/MS/MS analysis. The LC/MS/MS system was composed with Waters alliance 2695 XELC/MS/MS (Waters, Watford, UK) and Zobax SB-C18 $(5 \mu \mathrm{m}, 4.6 \times 250 \mathrm{~mm}$, Agilent, USA). Separation was accomplished with a gradient mode: mobile phase $A$, water: mobile phase $B$, acetonitrile: flow rate $0.3 \mathrm{~mL} / \mathrm{min}$, and ratio of $\mathrm{A}$ to $\mathrm{B}: 0-3 \mathrm{~min}, 70: 30 ; 3-4 \mathrm{~min}$, from $70: 30$ to $95: 5 ; 4-6 \mathrm{~min}$, from $95: 5$ to $100: 0 ; 6-25 \mathrm{~min}$, $100: 0 ; 25-30 \mathrm{~min}$, from $100: 0$ to $70: 30$. The Waters alliance 2695 Quattro Premier XE was used in negative ion ESI mode. The electrospray ionization (ESI) settings were as follows: capillary voltage, $3.5 \mathrm{kV}$; cone voltage, $40 \mathrm{~V}$; desolvation gasflow (Argon gas), $800 \mathrm{~L} / \mathrm{hr}$; cone gas-flow, $20 \mathrm{~L} / \mathrm{hr}$; collision energy, $20 \mathrm{~V}$. To determine concentrations of the free forms of phenols, we followed the procedures described above except enzyme hydrolysis.

2.3. Statistical Analyses. Distribution normality of the phenols levels was tested with Shapiro-Wilk $W$ test. If their probability $(W)$ is $<0.05$, their distribution is considered not to follow normal distribution.

"Nondetectable" was assigned a value of half of the minimum value of detected each phenol level for further statistical analyses. Considering each value's characteristic (normality and nominal, continuous, or ordered values), Wilcoxon test, Fisher's exact test, Spearman's rho, and regression analysis were used for the study analyses. $P<0.05$ was considered to be statistically significant. The statistical package of JMP Version 4 (SAS Institute, Cary, NC, USA) was used for all analyses.

\section{Results}

3.1. Characteristics of Study Subjects. The characteristics of the subjects are summarized in Table 1. Mothers were 30.67 \pm 3.45 years old, and, as expected, their body mass indices (BMIs) were increased during the pregnancy (median of before and after: 20.19 and $23.53 \mathrm{~kg} / \mathrm{m}^{2}$, resp.). Based upon education level, occupation, and monthly household income, participants reflected typical middle class in the Republic of Korea. Approximately, $11 \%(N=35)$ of the mother have clinical disease $(s)$, such as toxemia $(N=22)$, thyroid disorders $(N=6)$, and gastritis $(N=1)$. Similar number of 
TABLE 1: Characteristics of subjects.

(a) Mothers

\begin{tabular}{|c|c|}
\hline Items & $\%(N=325)$ \\
\hline \multicolumn{2}{|l|}{ Health status } \\
\hline Normal & 89.2 \\
\hline Disease $^{\mathrm{a}}$ & 10.8 \\
\hline \multicolumn{2}{|l|}{ Education } \\
\hline$\leq 9 \mathrm{yrs}$ & 0.3 \\
\hline$>9 \mathrm{yrs}$ and $\leq 12 \mathrm{yrs}$ & 22.4 \\
\hline$>12$ yrs and $\leq 16$ yrs & 69.4 \\
\hline$>16$ yrs & 7.9 \\
\hline \multicolumn{2}{|l|}{ Job } \\
\hline House wife & 43.0 \\
\hline Office workers & 21.7 \\
\hline Teachers & 10.8 \\
\hline Others & 24.5 \\
\hline \multicolumn{2}{|l|}{ Monthly income } \\
\hline$<\$ 2,000$ & 17.1 \\
\hline$\$ 2,000 \sim \$ 4,000$ & 55.7 \\
\hline$>\$ 4,000$ & 27.2 \\
\hline \multicolumn{2}{|l|}{ Food intake } \\
\hline Vegetable preferred & 16.9 \\
\hline Meat preferred & 14.7 \\
\hline Fish preferred & 14.3 \\
\hline Evenly & 53.9 \\
\hline \multicolumn{2}{|c|}{ Consumption of dairy products ${ }^{b}$} \\
\hline $1 \sim 2$ times/month & 11.3 \\
\hline Once/week & 12.0 \\
\hline $2 \sim 3$ times/week & 40.8 \\
\hline Every day & 35.9 \\
\hline \multicolumn{2}{|l|}{ Use of detergents for food } \\
\hline Rare & 1.0 \\
\hline 2 3 times/week & 11.2 \\
\hline Every time & 87.8 \\
\hline \multicolumn{2}{|l|}{ Use of cosmetics } \\
\hline 1-2 times/month & 24.1 \\
\hline Once/week & 20.6 \\
\hline $2 \sim 3$ times/week & 27.3 \\
\hline Every day & 28.0 \\
\hline \multicolumn{2}{|l|}{ Alcohol drinking $^{\mathrm{c}}$} \\
\hline Never & 29.1 \\
\hline 1-2 times/month & 47.7 \\
\hline Once/week & 46.2 \\
\hline$\geq 2$ times/week & 7.0 \\
\hline \multicolumn{2}{|l|}{ Tobacco smoking } \\
\hline Never smoker & 88.07 \\
\hline Ex-smoker $^{\mathrm{d}}$ & 11.58 \\
\hline Smoker & 0.35 \\
\hline \multicolumn{2}{|c|}{${ }^{\mathrm{a}}$ Toxemia, thyroid disorders, gastritis, and so forth. } \\
\hline \multicolumn{2}{|l|}{${ }^{\mathrm{b}}$ Milk, cheese, and so forth. } \\
\hline${ }^{\mathrm{c}}$ Before pregnant. & \\
\hline${ }^{\mathrm{d}}$ Quitted smoking over 1 & \\
\hline
\end{tabular}

(b) Infants $(N=326)$

\begin{tabular}{lc}
\hline Items & $39.1 \pm 1.5$ \\
\hline Embryonic period (wks) & $3.2 \pm 0.4$ \\
\hline
\end{tabular}

(b) Continued.

\begin{tabular}{lc}
\hline Items & \\
\hline Stature $(\mathrm{cm})$ & $50.2 \pm 2.3$ \\
Health status (\%) & 88.7 \\
$\quad$ Normal & 5.0 \\
$\quad$ Disease ${ }^{\mathrm{a}}$ & 6.3 \\
$\quad$ Recovered & \\
${ }^{\mathrm{a}}$ Jaundice $(N=6)$, intestinal obstruction $(N=2)$, congenital \\
malformation $(N=2)$, enteritis $(N=1)$, cyanosis $(N=1)$, and so forth. \\
bJaundice $(N=7)$, respiratory distress $(N=5)$, conjunctivitis $(N=1)$, \\
dyspepsia $(N=1)$, acute enteritis $(N=1)$, and so forth.
\end{tabular}

the infants were sick at birth $(N=34)$, and most of the sick babies were recovered within 2 weeks after birth or on the therapy except two infants who were born with a congenital malformation. There was no association of disease presence between the mothers and their infants $(P=0.66)$.

3.2. Exposure Levels of the Three Phenols in Milk. We established a sensitive analytical method to measure BPA and APs in colostrum samples with LC/MS/MS. Limit of detection (LOD) and limit of quantification (LOQ) were calculated with signal to noise ratio 10 and 30, respectively. The calibration curve for simultaneous analyses of the three phenols was obtained within 5 different concentrations in phenols-spiked milk. The recoveries of BPA, NP, and OP were over $80 \%$.

The distributions of the three phenols were left skewed near to zero, that is, nondetectable values and did not follow normal distributions $(P s<0.01$ by Shapiro-Wilk $W$ test for nonnormality). Ranges of the three phenols' levels in colostrum were shown in Table 2. OP and NP were not detected in most colostrum samples as free forms without any metabolism. In addition, there was a significant positive correlation between total OP and NP levels $(\beta=0.37$, $P<0.01$ by regression analysis) and somewhat positive association between total $\mathrm{OP}$ and BPA levels $(\beta=0.06$, $P=0.09$ ).

Finally, we could estimate the daily exposure to the phenols in the infants via their mothers' milk and determined that the current exposure levels to BPA and NP were lower than their tolerable daily intakes (TDIs) (Table 2).

3.3. Exposure Routes of the Phenols in Mothers. To identify the potential routes of phenols exposure from environment, we investigated associations between phenol levels in colostrum and exposure sources. We observed that dairy products intake and detergents use were positively correlated with total BPA levels $(P<0.05)$ (Table 3$)$. However, we did not find any statistically significant association between phenol levels and other exposure (Table 3 ) including air pollution at resident area or use of plastic wrap.

3.4. Effects of Phenol Exposures on Mother and Infant Health. Considering no associations between mothers' and infants' disease presence, we separately analyzed effects of phenol exposure on mothers or infants. At first, we analyzed effects of 
TABLE 2: Comparison between exposure levels and regulation levels of phenols.

\begin{tabular}{|c|c|c|c|c|c|c|}
\hline & Phenols & Detection of all samples (\%) & Median (ng/mL) & Range (ng/mL) & $\begin{array}{c}\text { Estimated daily } \\
\text { exposure in } \\
\text { neonates }^{\mathrm{a}, \mathrm{b}}(\mu \mathrm{g} / \mathrm{kg})\end{array}$ & TDI $(\mu \mathrm{g} / \mathrm{kg})^{\mathrm{c}}$ \\
\hline \multirow{3}{*}{ Free } & BPA & 39.8 & $<\mathrm{LOD}$ & $<$ LOD-54.2 & & \\
\hline & NP & 0.0 & $<\mathrm{LOD}$ & $<\mathrm{LOD}$ & & \\
\hline & OP & 2.9 & $<\mathrm{LOD}$ & $<$ LOD-14.1 & & \\
\hline \multirow{3}{*}{ Total } & $\mathrm{BPA}$ & 70.6 & 7.8 & $<$ LOD-57.3 & 1.20 & 50 \\
\hline & NP & 15.9 & $<\mathrm{LOD}$ & $<$ LOD-23.4 & 0.12 & $5-15^{\mathrm{d}}$ \\
\hline & OP & 27.5 & $<\mathrm{LOD}$ & $<$ LOD-30.9 & 0.02 & Unknown \\
\hline \multirow{3}{*}{ Conjugated } & $\mathrm{BPA}$ & 70.6 & 4.2 & $0.0-30.2$ & & \\
\hline & NP & 15.9 & $<\mathrm{LOD}$ & $0.0-23.4$ & & \\
\hline & OP & 27.5 & 0.0 & $0.0-30.7$ & & \\
\hline
\end{tabular}

${ }^{a}$ Nondetectible values were designated to half of the lowest value of each phenol.

${ }^{\mathrm{b}}$ Daily intake volume of milk in neonates, $500 \mathrm{~mL}$; mean body weight of the infants, $3.24 \mathrm{~kg}$; calculated from median level of each phenol $\times 500 / 3.24 / 1000$.

${ }^{c}[3,14]$.

${ }^{\mathrm{d}}$ NOAEL (no observable adverse effect level), $15 \mathrm{mg} / \mathrm{kg}$; uncertainty factor, 1000 (WHO) and 3000 (Danish Institute of Safe and Toxicology).

TABLE 3: Correlations between total phenol levels and candidates of exposure sources.

\begin{tabular}{|c|c|c|c|c|c|c|}
\hline & \multicolumn{2}{|l|}{$\mathrm{BPA}$} & \multicolumn{2}{|l|}{ OP } & \multicolumn{2}{|l|}{ NP } \\
\hline & Correlation coefficient $^{\mathrm{a}}$ & $P$ & Correlation coefficient & $P$ & Correlation coefficient & $P$ \\
\hline Consumption of dairy products & 0.36 & $0.02^{*}$ & 0.04 & 0.55 & -0.08 & 0.19 \\
\hline Use of detergents & 0.12 & $0.04^{*}$ & 0.07 & 0.29 & -0.06 & 0.32 \\
\hline Use of cosmetics & -0.05 & 0.39 & -0.05 & 0.43 & -0.04 & 0.48 \\
\hline Fish preference & -0.09 & 0.11 & -0.00 & 0.96 & -0.02 & 0.76 \\
\hline Alcohol drinking & 0.04 & 0.46 & -0.01 & 0.82 & -0.05 & 0.45 \\
\hline Tobacco smoking & -0.04 & 0.46 & -0.02 & 0.78 & -0.03 & 0.67 \\
\hline
\end{tabular}

${ }^{a}$ Spearman's $R$ ho by pair wise correlation analyses.

* Statistically significant.

phenols exposure on physiological characteristics. Mothers' age was not associated any phenol levels; however, embryonic period in neonates showed somewhat negative association with NP levels $(\beta=-0.25, P=0.09)$. Concerning phenols disposition at adipose sites, we studied effects of phenol exposure on BMI. As result, we found some positive associations between levels of mothers BMI (before and after delivery) and NP $(\beta=0.09, P=0.01$ and $\beta=0.04, P=0.19$, resp.) or $\mathrm{OP}(\beta=0.07, P=0.07$ and $\beta=0.03, P=$ 0.34 , resp.). However, there were some negative associations between mothers BMI (before and after delivery) and levels of BPA $(\beta=-0.11, P=0.07$ and $\beta=-0.09, P=0.12$, resp. $)$.

Secondly, we found that levels of total NP in mothers or infants with diseases were higher than those in health subjects (Table 4). In the case of mothers' toxemia, a major mother disease $(N=22)$, we found more strong association between the disease and NP exposure $(P<0.01)$. For neonates' major disease, jaundice ( $N=13$ including recovered cases), we could not find any significant association between the disease and the 3 phenol levels ( $P s>0.05)$. In addition, neonates with congenital malformation $(N=2)$ showed somewhat high levels of BPA, NP, and OP rather than others $(P=0.07$, 0.11 , and 0.27 , resp.). In detail, the colostrum of the infant with congenital malformation of uvulas showed quite high levels of total NP and OP (medians, 21.5 and $18.1 \mathrm{ng} / \mathrm{mL}$, resp.) compared to others' levels (medians $<\mathrm{LOD}$, i.e., $<0.5$ and $<0.3 \mathrm{ng} / \mathrm{mL}$, resp.).

\section{Discussion}

Considering physical complexity as a matrix of colostrum, proper preparations of colostrums specimens are required. Recently, many researchers have used solid phase extraction (SPE) for this purpose [6]. Considering broad use of BPA in plastic, we avoided SPE approach. Therefore, we performed liquid-liquid extraction; even this preparation was timeconsuming and labor intensive. In a case of biomonitoring environmental phenols, especially BPA, a general problem is background contamination during the analyses, which interfere with quantification at low concentrations of BPA. Therefore, we used glassware throughout the entire analytical procedure in order to avoid possible contamination of BPA. Blank tests, which were conducted with water instead of colostrum, were also performed at every daily experiment to confirm an absence of environmental phenol contamination in the whole of our experimental process. In addition, we tried to our best to avoid a drawback of LC/MS/MS analyses, for example, over estimation in low phenol-contained samples [20]. Thus, we established an optimal condition to 
TABLE 4: Association between health status and total phenol levels ${ }^{\mathrm{a}}$.

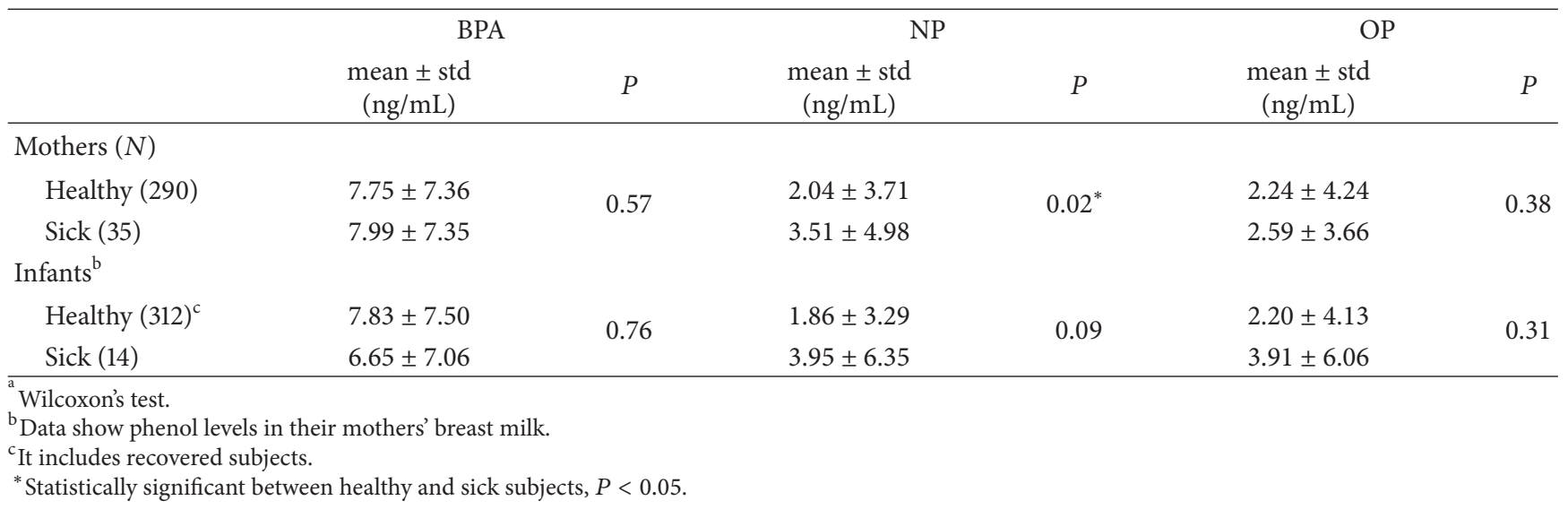

measure BPA, OP, and NP in the colostrum samples. We also performed analyses of HPLC/FLD to confirm LC/MS/MS results in low phenols samples (<medians of each phenol: $N=50)$ and obtained high reproducibility between two analyses (CVs $<15 \%)$.

Among the present 325 colostrum samples, $70.6 \%$ of them have detectable levels of BPA in colostrum (Table 2). Mendonca et al. recently reported similar detection frequency of BPA in USA-breast milk for 3-15 months infants, that is, $75 \%$ [21]. However, Völkel et al. detected BPA in $42 \%$ of infant urine [22]. Considering the relatively high frequency of BPA detection in colostrum samples, we suggest a high potential for exposure of breast-fed infants to BPA via colostrum. In addition, median level of total BPA $(7.8 \mathrm{ng} / \mathrm{mL})$ in the present colostrum study is somewhat higher than those in other biomonitoring studies with breast milk samples $[12,23,24]$. For example, another study with 101 colostrum samples detected BPA at a range of $1-7 \mathrm{ng} / \mathrm{mL}$ and a mean level of $3.41 \mathrm{ng} / \mathrm{mL}$ [25]. However, they used convenient ELISA methods and detected BPA in all samples without confirmation of BPA free system for analyses, for example, blank tests. Mendonca et al. also reported quite low levels of total BPA (median, $0.8 \mathrm{ng} / \mathrm{mL}$ ) in small number of infant breast milk samples $(N=23)$ [21].

On the basis of three phenol levels in colostrum, volume of daily intakes of milk $(500 \mathrm{~mL})$, and mean body weight of the baby subjects $(3.24 \pm 0.46 \mathrm{~kg})$, we estimated the daily exposure of infants to BPA, OP, and NP (Table 3 ). The estimated exposure levels of BPA and NP via colostrum in Korean neonates appear to be safe, compared to their TDIs $[3,8]$. In a case of OP, we cannot determine whether the present exposure status of OP is acceptable or not at this point because there is no reference dose data of OP. When we compared the daily exposure levels in the present neonate to those in adults, they may be highly exposed to phenols due to body burden. For example, the neonates may be $\approx 10$-fold highly exposed to BPA than adults [1.2 ug/ $\mathrm{kg}$ (Table 3 )] versus $\approx 0.13 \mathrm{ug} / \mathrm{kg}$, which was estimated from Korean adult urines [14].

Concerning EDCs' disposition, many researchers have analyzed EDCs at adiposities. As lipophilic characteristics of EDCs can induce chronic diseases even with buffering of acute toxicity, this issue has been emphasized. A recent Spanish study showed that the most obese woman had the highest levels of NP and PCBs in adipose tissue [26]. However, it is not clear, yet, whether body fat contents affect phenol accumulation in the body. In the present study, we found positive associations between levels of mothers BMI before delivery and NP or OP levels. However, BPA levels showed opposite trend, that is, negative association with mothers BMIs. For the reason of the opposite trend, we consider physiochemical difference in octanol-water partition coefficient value ( $\log P$ or Kow) between NP and BPA (4.48 and 3.32, resp.) [27]. In addition, people are simultaneously exposed to multiple EDCs; thus, we screened combined effects of BPA, NP, and OP on the present mothers' and neonates' health. However, the simple sum of total BPA, NP, and OP levels did not show any health risk. In order to study future and real combination effects of phenols or EDCs, their weight for risks or reliable simulation of multiple exposures should be considered.

Referring pharmacokinetics of phenols in human or rhesus monkeys $[28,29]$, which may be mainly metabolized into urine as conjugated forms with glucuronyl or sulfonyl groups, we have used conjugated BPA for biomonitoring of BPA in urine or blood samples $[14,15,30]$. Detoxification enzymes which metabolize free phenols into conjugated phenols are known to decrease in pregnant women [31]. As most conjugated BPA was analyzed in urine, we analyzed $\mathrm{BPA}$ in some urines among the present mothers who donated urine $(N=21)$ to confirm conjugation capacity in the present mothers. Their conjugated BPA levels in urine were approximately half of those in colostrum (mean \pm std, $0.98 \pm 1.96 \mathrm{ug} / \mathrm{L}$ versus $2.44 \pm 3.68 \mathrm{ug} / \mathrm{L}$, mean difference, $-1.46 \mathrm{ug} / \mathrm{L}$.) When we compared the conjugated BPA levels in the present lactating mothers' urine samples to those in other adults' [14], they were quite lower than the others (median, $<0.6 \mathrm{ng} / \mathrm{mL}$ versus $7.86 \mathrm{ng} / \mathrm{mL}$ ). It may support pregnant women' loss of detoxification enzyme activity, even though we consider the decline of BPA exposure due to years [32].

We also studied exposure of routes of the phenols in mothers and found association between BPA levels and 
consumption of dairy products (Table 3). Dairy food always needs its storage, packing, or some manufacturing. The real parts, which people intake, directly contact to containers or packing materials rather than other food. Like PCBs accumulation in perennial fish [3], accumulation of BPA in cow can be thought via food chain. Interestingly, we also found a positive association between BPA levels and use of detergents for food. A recent report [33] concerning the "effect of detergents in the release of bisphenol A from polycarbonate baby bottles" can support our result. Referring reports of AP-related food [16, 17], we studied more other sources for APs, but we could not find any similar source, for example, fish, fruit, or fish oil.

Considering health risks of phenols, we found negative association between embryonic period in neonates and their colostrum NP levels and suspect NP induces embryonic instability. NP showed some embryotoxicity in crustaceans and oysters, for example, low survival rates and poor embryonic and larval development $[34,35]$. However, experimental studies in mammals to clarify effects of NP on embryonic period have been thoroughly performed, yet. Thus, future enlarged epidemiological studies or experimental studies are required to confirm risks of NP on embryonic stability. Secondly, we found that levels of total NP in sick mothers, particularly, toxemia-patients, were higher than those in health subjects (Table 4). In addition, we found that the infant with congenital malformation of uvulas showed quite high levels of total APs in compared to others' levels. Thus, our finding should be further confirmed in enlarged studies, even though the present subjects well represent the Korean women in childbed from similar proportion of toxemia or gestational complications [36].

In conclusion, we found that most of neonates are exposed to BPA rather than NP or OP via colostrums. Although current exposure levels of the phenols are safe based upon their TDIs, we suggest continuous biomonitoring of them to clarify their unclear health risk on neonates and pregnant or gestation mothers.

\section{Acknowledgment}

This work was supported by the SRC Research Center for Women's Diseases of Sookmyung Women's University (2010).

\section{References}

[1] R. M. Sharpe, "Hormones and testis development and the possible adverse effects of environmental chemicals," Toxicology Letters, vol. 120, no. 1-3, pp. 221-232, 2001.

[2] G. G. Ying, B. Williams, and R. Kookana, "Environmental fate of alkylphenols and alkylphenol ethoxylates-a review," Environment International, vol. 28, no. 3, pp. 215-226, 2002.

[3] M. Yang, M. S. Park, and H. S. Lee, "Endocrine disrupting chemicals: human exposure and health risks," Journal of Environmental Science and Health Part C, vol. 24, pp. 183-224, 2006.

[4] A. M. Calafat, Z. Kuklenyik, J. A. Reidy, S. P. Caudill, J. Ekong, and L. L. Needham, "Urinary concentrations of bisphenol A and 4-nonylphenol in a human reference population," Environmental Health Perspectives, vol. 113, no. 4, pp. 391-395, 2005.
[5] W. Dekant and W. Völkel, "Human exposure to bisphenol A by biomonitoring: methods, results and assessment of environmental exposures," Toxicology and Applied Pharmacology, vol. 228, no. 1, pp. 114-134, 2008.

[6] A. M. Calafat, X. Ye, L. Y. Wong, J. A. Reidy, and L. L. Needham, "Exposure of the U.S. population to bisphenol A and 4-tertiaryoctylphenol: 2003-2004," Environmental Health Perspectives, vol. 116, no. 1, pp. 39-44, 2008.

[7] T. J. Murray, R. G. Lea, D. R. Abramovich, N. E. Haites, and P. A. Fowler, "Endocrine disrupting chemicals: effects on human male reproductive health," Early Pregnancy, vol. 5, no. 2, pp. 80112,2001

[8] W. Völkel, M. Kiranoglu, and H. Fromme, "Determination of free and total bisphenol A in human urine to assess daily uptake as a basis for a valid risk assessment," Toxicology Letters, vol. 179, no. 3, pp. 155-162, 2008.

[9] L. Zanieri, P. Galvan, L. Checchini et al., "Polycyclic aromatic hydrocarbons (PAHs) in human milk from Italian women: influence of cigarette smoking and residential area," Chemosphere, vol. 67, no. 7, pp. 1265-1274, 2007.

[10] K. Abraham, O. Päpke, A. Gross et al., "Time course of $\mathrm{PCDD} / \mathrm{PCDF} / \mathrm{PCB}$ concentrations in breast-feeding mothers and their infants," Chemosphere, vol. 37, no. 9-12, pp. 1731-1741, 1998.

[11] K. Hooper, M. X. Petreas, T. Chuvakova et al., "Analysis of breast milk to assess exposure to chlorinated contaminants in Kazakstan: high levels of 2,3,7,8-tetrachlorodibenzo-p-dioxin (TCDD) in agricultural villages of southern Kazakstan," Environmental Health Perspectives, vol. 106, no. 12, pp. 797-806, 1998.

[12] Y. Sun, M. Irie, N. Kishikawa, M. Wada, N. Kuroda, and K. Nakashima, "Determination of bisphenol A in human breast milk by HPLC with column-switching and fluorescence detection," Biomedical Chromatography, vol. 18, no. 8, pp. 501-507, 2004.

[13] T. Isobe, H. Nishiyama, A. Nakashima, and H. Takada, "Distribution and behavior of nonylphenol, octylphenol, and nonylphenol monoethoxylate in Tokyo metropolitan area: their association with aquatic particles and sedimentary distributions," Environmental Science and Technology, vol. 35, no. 6, pp. 1041-1049, 2001.

[14] M. Yang, S. Y. Kim, S. S. Chang, I. S. Lee, and T. Kawamoto, "Urinary concentrations of bisphenol A in relation to biomarkers of sensitivity and effect and endocrine-related health effects," Environmental and Molecular Mutagenesis, vol. 47, no. 8, pp. 571-578, 2006.

[15] M. Yang, S. Y. Kim, S. M. Lee et al., "Biological monitoring of bisphenol A in a Korean population," Archives of Environmental Contamination and Toxicology, vol. 44, no. 4, pp. 546-551, 2003.

[16] K. Guenther, V. Heinke, B. Thiele, E. Kleist, H. Prast, and T. Raecker, "Endocrine disrupting nonylphenols are ubiquitous in food," Environmental Science and Technology, vol. 36, no. 8, pp. 1676-1680, 2002.

[17] G. W. Chen, W. H. Ding, H. Y. Ku et al., "Alkylphenols in human milk and their relations to dietary habits in central Taiwan," Food and Chemical Toxicology, vol. 48, no. 7, pp. 1939-1944, 2010.

[18] USEPA, "Nonylphenol and nonylphenol ethoxylate action plan," RIN 2070-ZA09, 2010.

[19] M. Yang, S. Kim, E. Lee et al., "Sources of polycyclic aromatic hydrocarbon exposure in non-occupationally exposed Koreans," Environmental and Molecular Mutagenesis, vol. 42, no. 4, pp. 250-257, 2003. 
[20] B. Yi, C. Kim, and M. Yang, "Biological monitoring of bisphenol A with HLPC/FLD and LC/MS/MS assays," Journal of Chromatography B, vol. 878, no. 27, pp. 2606-2610, 2010.

[21] K. Mendonca, R. Hauser, A. M. Calafat, T. E. Arbuckle, and S. M. Duty, "Bisphenol A concentrations in maternal breast milk and infant urine," International Archives of Occupational and Environmental Health, 2012.

[22] W. Völkel, M. Kiranoglu, and H. Fromme, "Determination of free and total bisphenol A in urine of infants," Environmental Research, vol. 111, no. 1, pp. 143-148, 2011.

[23] X. Ye, Z. Kuklenyik, L. L. Needham, and A. M. Calafat, "Measuring environmental phenols and chlorinated organic chemicals in breast milk using automated on-line column-switching-high performance liquid chromatography-isotope dilution tandem mass spectrometry," Journal of Chromatography B, vol. 831, no. 1-2, pp. 110-115, 2006.

[24] L. N. Vandenberg, I. Chahoud, J. J. Heindel, V. Padmanabhan, F. J. R. Paumgartten, and G. Schoenfelder, "Urinary, circulating, and tissue biomonitoring studies indicate widespread exposure to bisphenol A," Environmental Health Perspectives, vol. 118, no. 8, pp. 1055-1070, 2010.

[25] R. Kuruto-Niwa, Y. Tateoka, Y. Usuki, and R. Nozawa, "Measurement of bisphenol A concentrations in human colostrum," Chemosphere, vol. 66, no. 6, pp. 1160-1164, 2007.

[26] M. J. Lopez-Espinosa, C. Freire, J. P. Arrebola et al., "Nonylphenol and octylphenol in adipose tissue of women in Southern Spain," Chemosphere, vol. 76, no. 6, pp. 847-852, 2009.

[27] X. Peng, Z. Wang, B. Mai et al., “Temporal trends of nonylphenol and bisphenol A contamination in the Pearl River Estuary and the adjacent South China Sea recorded by dated sedimentary cores," Science of the Total Environment, vol. 384, no. 1-3, pp. 393-400, 2007.

[28] W. Völkel, T. Colnot, G. A. Csanády, J. G. Filser, and W. Dekant, "Metabolism and kinetics of bisphenol a in humans at low doses following oral administration," Chemical Research in Toxicology, vol. 15, no. 10, pp. 1281-1287, 2002.

[29] J. A. Taylor, F. S. vom Saal, W. V. Welshons et al., "Similarity of bisphenol A pharmacokinetics in rhesus monkeys and mice: relevance for human exposure," Environmental Health Perspectives, vol. 119, no. 4, pp. 422-430, 2011.

[30] M. Yang, J. H. Ryu, R. Jeon, D. Kang, and K. Y. Yoo, "Effects of bisphenol A on breast cancer and its risk factors," Archives of Toxicology, vol. 83, no. 3, pp. 281-285, 2009.

[31] E. Hodgson, A Text Book of Modern Toxicology, Wiley, Hoboken, NJ, USA, 2010.

[32] A. Matsumoto, N. Kunugita, K. Kitagawa et al., "Bisphenol A levels in human urine," Environmental Health Perspectives, vol. 111, no. 1, pp. 101-104, 2003.

[33] J. Maia, J. M. Cruz, R. Sendón, J. Bustos, J. J. Sanchez, and P. Paseiro, "Effect of detergents in the release of bisphenol A from polycarbonate baby bottles," Food Research International, vol. 42, no. 10, pp. 1410-1414, 2009.

[34] H. E. Nice, D. Morritt, M. Crane, and M. Thorndyke, "Longterm and transgenerational effects of nonylphenol exposure at a key stage in the development of Crassostrea gigas. Possible endocrine disruption?" Marine Ecology Progress Series, vol. 256, pp. 293-300, 2003.

[35] G. A. LeBlanc, X. Mu, and C. V. Rider, "Embryotoxicity of the alkylphenol degradation product 4-nonylphenol to the crustacean daphnia magna," Environmental Health Perspectives, vol. 108, no. 12, pp. 1133-1138, 2000.
[36] Y. Yogev, N. Melamed, R. Bardin, K. Tenenbaum-Gavish, G. Ben-Shitrit, and A. Ben-Haroush, "Pregnancy outcome at extremely advanced maternal age," American Journal of Obstetrics and Gynecology, vol. 203, no. 6, pp. 558.e1-558.e7, 2010. 


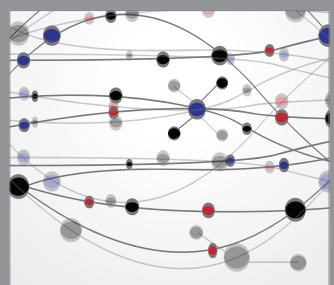

The Scientific World Journal
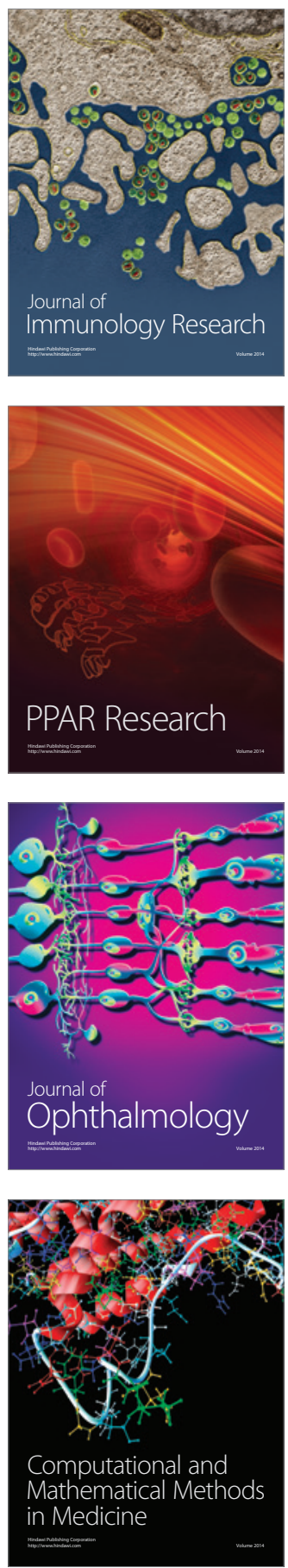

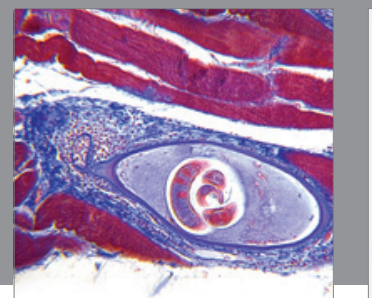

Gastroenterology

Research and Practice
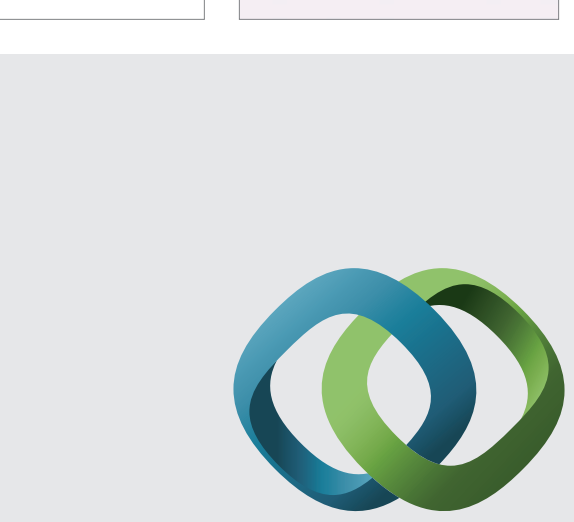

\section{Hindawi}

Submit your manuscripts at

http://www.hindawi.com
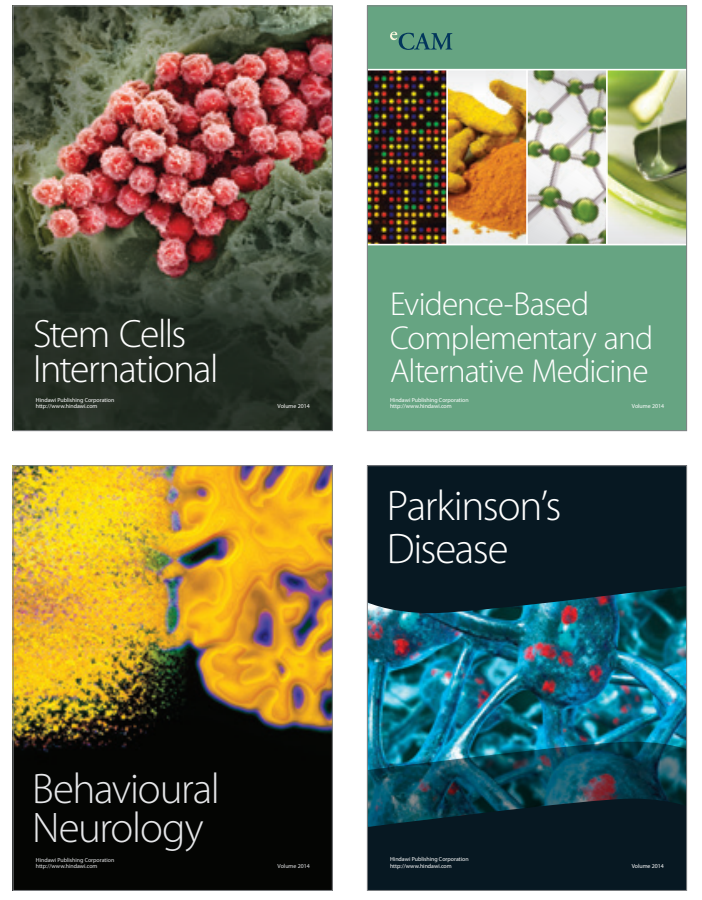
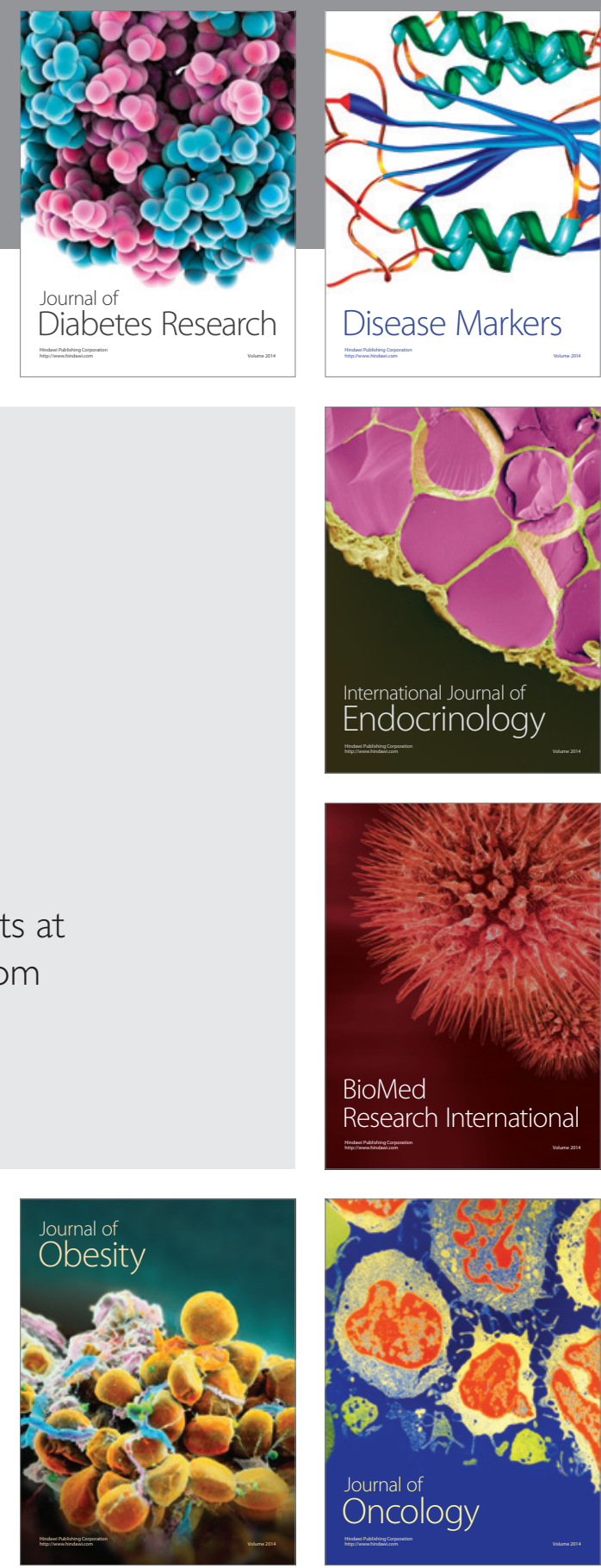

Disease Markers
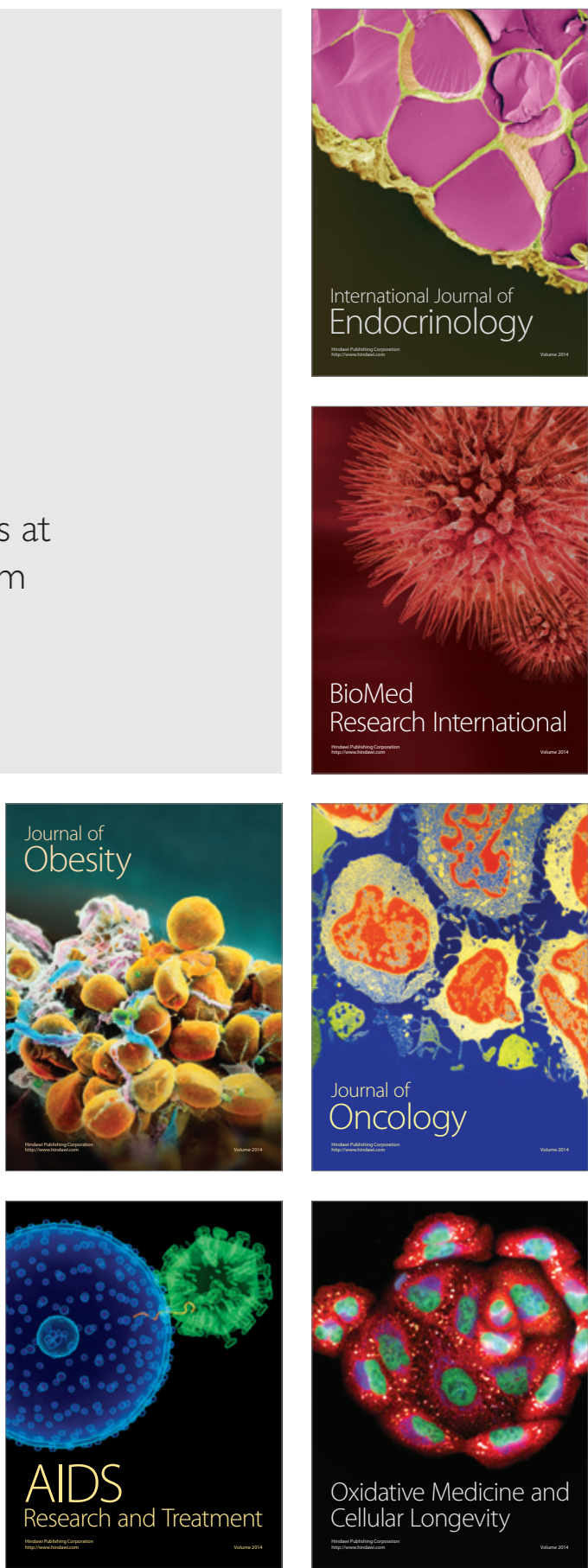